\title{
World Population Growth; Past, Present and Future
}

\author{
Environ Resource Econ (2013) 55:543-554 \\ DOI 10.1007/s10640-013-9675-6 \\ John Cleland
}

Past, current and projected future population growth is outlined. Barring a calamitous pandemic, a further increase in the world's population from 7 to between 8.8 and 10 billion by mid-century is unavoidable. This increase is driven by high fertility in subSaharan Africa whose population is forecast to more than double in the next 40 years and by a modest rise of $23 \%$ in Asia's huge population. Beyond mid-century, the range of plausible demographic destinations widens; much depends on fertility rates in the next few decades because they will determine the number of potential reproducers in the second half of the century. Vigorous promotion of family planning, particularly in Africa, is crucial to achievement of population stabilisation. Unchanged fertility implies a global population of 25 billion by the end of the century. In the next few decades the contribution of human population growth to global environmental change is moderate, because nearly all growth will occur in poor countries where consumption and emission of greenhouse gases is low. The implications for food production, and thereby water consumption, are greater. Much of the future need for food will be driven by increased numbers rather than changing diets. Loss of bio-diversity and natural habitats, degradation of fragile eco-systems due to over-exploitation and aquifer deletion are likely consequences.

\section{The Demographic transition and historical population growth}

. The rise in human numbers is best understood through the framework of the demographic transition. Before this transition births and deaths were approximately in balance and population increase was very slow. Life expectancies fluctuating in the range of 20 to 40 years were matched by fertility of 4.5 to 6.0 births per woman. On average, about two children per couple survived to adulthood, a level that maintains a stable population size. Successful reproduction was a lottery; some parents had many surviving children, others none. The adjustment to this chance variation was obvious; children flowed from those with reproductive excess to those with a deficit through adoption, fostering and early apprenticeships. Infanticide was a further post-natal means of controlling family size, particularly in Asia.

In the absence of any constraints, it is estimated that, on average, women would have about 15 live births. The wide gap between this maximum and observed fertility is largely explained by extended breastfeeding that widened inter-birth intervals and by 
checks on pre-marital sexual access operating in tandem with delayed marriage. Whether or not our ancestors practised forms of birth control is hotly contested. Techniques of abortion were certainly known in most pre-transitional societies but the effective ones were too dangerous to be used except in extreme situations. The link between coitus and conception was recognised and thus abstinence, non-penetrative intercourse, anal intercourse and coitus interruptus, at least in principle, were available to those wishing to avoid pregnancy, though all except abstinence were probably regarded with moral abhorrence in many societies. These ways of avoiding pregnancy may have been deployed in times of great hardship to postpone births but their routine widespread use to limit family size is a recent phenomenon.

The classic demographic transition model outlines the sequence by which societies are transformed from a pre-transitional balance of high mortality and fertility to a new balance of low vital rates, though, as discussed later, a post-transitional era in which deaths exceed births was not foreseen. The transition is initiated by improvements in life expectancy which usher in a period of population growth. After a lag, which varies greatly in length, fertility falls, due primarily to increased contraception, but populations continue to grow for several decades even after the advent of low fertility, because of the effects of age structure, a feature called population momentum. The first phase of transition when mortality has declined but fertility remains high gives rise to large cohorts of surviving children and, as these swollen cohorts enter the reproductive age span, the total numbers of births and the crude birth rate are bolstered even when the number of births per couple is small. In the final phase of demographic transition, the large cohorts inflate the old-age population; population growth ceases and may even become negative.

The crucial role of changing age structure is well illustrated by the case of the Republic of Korea (Fig 1). By 1960, mortality had already declined but fertility remained high at about six births per woman and the population was growing at $2.8 \%$ per year. At that time, $42 \%$ of the total population was aged less than 15 years but only $3 \%$ were aged 65 or more. In the next 40 years, fertility fell sharply and by 2000 the number of births per woman was very low at about 1.4 but the growth rate remained positive at $0.6 \%$ per year because the percent of all females in the reproductive age span peaked at $57 \%$ in the last decade of the $20^{\text {th }}$ century. Between 2000 and 2040 it is projected that the proportion of Korea's population aged 65 or more will rise from $7.4 \%$ to $30.5 \%$ and the percent of females in the reproductive ages will fall from $57 \%$ to $35 \%$.

Fig 1

The faltering start of demographic transition may be traced back to the $18^{\text {th }}$ century. Between the years $1 \mathrm{AD}$ and 1700, human population grew at the imperceptibly slow pace of $0.06 \%$ per year, implying a doubling time of 1200 years (Madison 2007). This rate accelerated in the $18^{\text {th }}$ century to $0.46 \%$ and further to over $0.5 \%$ in the next century. Much of this early increase occurred in Europe and its overseas settlements and reflects the effect on mortality of a combination of rising living standards (and thus 
improved nutrition) and better control of infectious diseases. Globally, however, life expectancy and population growth remained low until the second half of the $20^{\text {th }}$ century. Dyson (2010) estimates world life expectancy and the rate of population growth in 1900 to be 25 years and $0.6 \%$, respectively, rising modestly to 30 years and $0.9 \%$ by 1950 . Thereafter, the pace of change increased dramatically. Mass application of modern preventive health measures in the poor countries of Asia, Latin America and Africa and better transport to relieve local food shortages resulted in large falls in death rates, particularly among infants and children. By 1960, world life expectancy had jumped to 48 years and continued to improve to reach 67 years in 2010 .

Because of these rapid gains in survival following the World War II while fertility remained largely unchanged, the rate of population growth peaked in the $1960 \mathrm{~s}$ at $2 \%$ per year. The rate then began to drop in response to falling fertility, down to $1.2 \%$ in the decade 2000-2010. In absolute numbers, the increase in the world's population peaked two decades later in the 1980s when an increment of 850 millions was recorded in a decade, a staggering figure that almost equals total world population in 1800 (Figure 2). In a mere 50 years, between 1950 and the end of the century, world population rose from 2.5 to 6.1 billions.

Fig 2

Population growth in the major world regions over the past 60 years has not been uniform (Table 1) At one extreme Europe's population grew by $35 \%$ while, at the other, sub-Saharan Africa saw a 4.6 fold increase, followed by the Arab States of North Africa with a quadrupling of population. The population of the United States and Canada doubled, partly because of a large contribution from migration, while Asia's population trebled and Latin America recorded a 3.5 fold increase. In terms of absolute contribution to the global growth of 4.4 billion, Asia dominated, accounting for $63 \%$ of the increase but this simply reflects the huge baseline size of Asia. In these 60 years the regional distribution of population changed radically. For example in 1950 Europe's population was three times larger than that of sub-Saharan Africa. By 2010, it was smaller.

Table 1

\section{Current demographic situation}

Key features of the current demographic situation of major regions are shown in Table 2. Europe has the lowest fertility, well below the level of two births per woman required for long-term stability of population size, though this is offset by heavy net inmigration. For much of the past 50 years, annual fertility rates have been depressed by a steady increase in women's age at childbearing. Childbearing ages are now starting to stabilize and period fertility, as represented by the total fertility rate, has risen since 2000 . However, the level of childbearing remains chronically low, between 1.3 and 1.5 births, in much of Eastern Europe, Germany, Italy and Spain. In Germany low fertility reflects a high level of childlessness, estimated at $30 \%$ for the most recent cohort of women to have

reached the end of reproductive life (Breton and Prioux 2009). In Eastern and Southern Europe, the growing acceptance of a one child family is largely responsible. In the 
absence of migration, a fertility rate sustained at 1.3 births per woman implies, in the long term, a halving of population every 44 years while a rate of 1.5 implies a halving every 66 years. This prospect is welcome to many environmentalists but cause for despondency among politicians and economists, who are concerned about the consequences of a shrinking labour force that has to support a growing retiree population. Population ageing is discussed by Harper in this issue. In Northern America, the other post-transitional region, a higher fertility rate and a greater proportionate contribution from migration than in Europe act to sustain population growth at nearly $1 \%$ per year.

Table 2

In Asia, Latin America and Northern Africa, the transition to low mortality and fertility is well advanced. Life expectancy is close to 70 years and, in most countries of these regions, fertility has fallen from six or more births to below three in the past 50 years and is still declining. Rates of population growth in Asia and Latin America were not much greater in 2005-10 than in Northern America. Though the estimate of annual out-migration of 1.5 million for Asia looks large, it has little effect on population size, which is growing by 44 millions per year. In Latin America, by contrast, with an annual increase of six million, the exodus of about one million per year, mainly to Northern America, has acted as a significant brake on population growth.

Of course, regional averages hide marked inter-country variation and this is particularly true in Asia. In Japan, the forerunner of transition in this region, fertility has been below replacement level for many years; population growth has ceased and will turn negative unless hostile attitudes to in-migration change radically. Similarly, population growth is now low in China and the Republic of Korea at $0.5 \%$ and is expected to stop in about 15 years time. At the other extreme, population growth and fertility remain very high in Afghanistan, at 2.6\% and 6.6 births, respectively, and also high in Pakistan at $1.8 \%$ and 3.7 births. The northern Indian states of Uttar Pradesh and Bihar have a similar demographic profile to Pakistan. These two States contain a population of 306 million, $25 \%$ of India's total. Together with Pakistan's population of 174 million, they represent the main obstacle to population stability in Asia.

Sub-Saharan Africa is the clear regional outlier in terms of demographic modernization. Improvements in life expectancy halted between 1980 and 2000 because of HIV/AIDS and deteriorating economies. In the past decade, AIDS deaths have fallen and many African economies have flourished. Survival has improved but life expectancy, estimated to be 52.5 years in 2005-10 remains much lower than in other regions. Regional fertility and population growth remain high at about five births and $2.45 \%$, though much lower in Southern Africa.

\section{Future prospects}

International responsibility for population projections rests with the staff of the United Nations Population Division who revise estimates at two-yearly intervals. Prudently, in addition to a central, or medium, projection, high and low projections are also produced. A constant fertility projection is also available. These projections have been made since the 1950s and the accuracy of the medium projection in forecasting total world population over a forty year horizon is impressive, with an error typically below 3\% (Bongaarts and Bulatao 2000). Errors for specific countries can be large but tend to 
cancel each other in deriving the global total. The high/low and the medium projection projections differ only in the fertility assumption; fertility steadily diverges up/down to achieve a difference of 0.5 births per woman from the medium projection over a 15 year period and that difference is maintained over the remaining projection period. This highly simplified way of representing uncertainty reflects the fact that fertility, not mortality, is the main driver of future population size, though a mortality catastrophe that would seriously dent the current annual increase of about 75 millions in the world's population cannot be ruled out.

The difference of one birth between high and low projections seems modest and, for specific countries, the UN's spread of possible demographic futures is reasonable. It is less so for the world as a whole because it is highly unlikely that all countries would experience the same direction of divergence in fertility from the medium trajectory. For instance, the low fertility projection is plausible for sub-Saharan Africa but it is extremely implausible for those states in Europe and East Asia where the level of childbearing is already very low. For this reason, the high and low projections for the world are best interpreted as the very outer limits of plausibility.

The 2010 UN projections envisage global population to rise from 6.9 billion in 2010 to $8.1,9.3$ and 10.6 billion by mid-century under the low, medium or high assumptions (UN Population Division 2011). For reasons just outlined, a more realistic range might be half as wide, from, say, 8.8 to 9.9 billion. This magnitude of mid-century population is probably unavoidable and the narrow band of reasonable estimates could be cause for resignation and fatalism. Such attitudes would be both unjustified and dangerous. What happens to fertility in the next 40 years has huge implications for the final destination of the world's population because it will determine the number of potential reproducers in the second half of the century. By 2100 , the medium projection gives a population of around 10 billion with modest further growth. The low projection indicates a decline to 6.2 billion while the high projection yields a global population of 15.8 and still increasing. Thus the gap between low and high projections has widened to nearly 10 billion; even if this range is arbitrarily halved, the difference is still huge. And if fertility remains unchanged at the level of 2005-10, global population would exceed 25 billion by 2100 . Clearly, long-term sustainability of the planet depends on what happens to human reproduction in this and the next generation.

Returning to the relative comfort of the UN's medium projections for the next 40 years, table 3 shows the likely changes for major regions, together with the total fertility rate expected by 2045-50. The fertility assumptions are critical. The recent rise in European birth rates is expected to continue. There are sound reasons to doubt this scenario but, whatever the eventuality, it will make only a minor difference to the global situation. Of far greater consequence is the assumption that in Asia (and Latin America), fertility will drop slightly below replacement level. The assumption can muster considerable support. China's fertility will almost certainly remain below-replacement level because of rapid urbanization and rising material aspirations. Abandonment of the Government's population control policy is unlikely to make much difference; Chinese 
populations unaffected by the policy, such as those in Singapore, Taiwan and Hong Kong, all have extremely low fertility.

Fertility prospects in India, soon to become the world's most populous nation, are less certain. In the four southern States, Kerala, Tamil Nadu, Karnataka and Andhra Pradesh, replacement level fertility has already been reached and further declines are possible. In the most recent national survey of 2005/6, between $26 \%$ and $39 \%$ of women with one child in Kerala, Tamil Nadu, Maharastra and Punjab reported a desire for no more children and the reproductive preferences of husbands were similar (IIPS 2007). These figures would be much higher in the absence of the desire to have a son. It appears that a one-child family in parts of India may become acceptable, as has already occurred in Eastern and Southern Europe and much of East Asia. What happens in the high fertility states of northern India and Pakistan, however, depends in part on policies and programmes that will be discussed in the next section.

Table 3

The other really important fertility assumption concerns sub-Saharan Africa. In its 2008 projections, the UN assumed that fertility would fall from its current level of about five births per woman to 2.5 by mid-century. In response to evidence that the fertility decline in this region was faltering, the forecast was raised from 2.5 to 3.0 births. A fall of two births in 40 years is modest relative to the experience of other regions and may prove to be too conservative. Much depends on actions to promote family planning.

The critical contribution of sub-Saharan Africa to global population growth in the next 40 years is clearly seen in Table 3 . Its population is forecast to more than double, accounting for nearly half of the global increase of 2.4 billion. The other big contributor is Asia but in this region the percent increase is modest (23\%) and much of it is due to age structure rather than high fertility. By comparison, the contributions of other regions are minor, at least in purely numerical terms, though more important for resourceconsumption and the environment. The population of Europe, despite migration and the assumption of rising fertility, is expected to decline slightly but an appreciable increase of 100 million is forecast for Northern America, largely fuelled by migration. To the extent that migrants to USA and Canada adopt the consumption and $\mathrm{CO} 2$ emission habits of the host population, the environmental impact will be far greater than that implied by the mere population numbers. In USA, 70\% of adults are overweight. If all countries had the same body mass index as in USA, total human biomass would increase by $20 \%$ and the additional energy requirements would be equivalent to an extra 473 million people of average body mass (Walpole et al 2012).

\section{The role of policies and programmes}

Increased contraceptive use was undoubtedly the main direct determinant of the fertility declines of the past century, though abortion (both legal and illegal) and rising marriage ages have also made appreciable contributions. The key policy question concerns the extent to which state promotion of modern contraceptive methods can accelerate reproductive change in Africa and the remaining high fertility areas of Asia. At 
the outset, it should be recognized that government-sponsored family planning programmes are not a fundamental or necessary cause of fertility decline. After all, fertility in many European countries fell to very low levels in the 1930s despite government hostility or indifference to contraception and without the benefit of highly effective methods.

More recent examples of steep falls in birth rates in the absence of appreciable government intervention include Brazil and Burma. When motives are very strong, couples will find ways to control reproduction and, in the absence of legal restrictions, a market in contraceptives will emerge. In Brazil, pharmaceutical companies promoted oral contraceptives through commercial outlets while doctors performed illicit sterilisations under the guise of caesarean sections (Potter et al 2001). This truth lies behind an enduring scepticism that programmes can exert more than a trivial influence on reproduction ( Pritchett 1994). Instead, it is proposed that investments in child survival, education, women's empowerment and poverty-reduction are better alternatives to achieve population stabilisation than investment in family planning. These factors are certainly conducive to fertility decline. Improvements in mortality are a pre-condition for large sustained falls in fertility and the level of adult education, particularly of women, is a strong correlate. However, 40 years of research has failed to identify clear thresholds of development that need to be attained before reduced childbearing is possible. It is also both patronising and false to assume that poor illiterate couples necessarily need or want large numbers of children. It is true that such couples usually do have more children than privileged strata but this is largely because unwanted child bearing is higher. Survey data from 41 developing countries, show that the poorest quintile experienced on average 1.2 unwanted births compared with 0.5 births among the richest quintile (Gillespie et al 2007).

Moreover, abundant evidence has accumulated in the last 40 years that contraception is not seamlessly incorporated into reproductive behaviour, whenever the need arises. On the contrary, it often encounters serious initial resistance, evoking anxieties, fear and even moral outrage at a radical innovation that affects 'such a central feature of life (Casterline, Sathar and Haque 1991; Ruttenberg and Watkins 1997). These anxieties are typically expressed as concerns about the side effects and damage to health of modern methods, the most commonly stated reason given for non-use (Sedge et al. 2007). The translation into contraceptive behaviour of motives to postpone or stop childbearing is also impeded by lack of information, access and affordability and by unnecessary medical restrictions (Campbell, Sahin-Hodogglugil and Potts 2006).

These barriers are the origin of widespread unmet need for family planning (ie non-use among women wanting no child for at least two years), the high proportion of pregnancies reported by women in surveys as unintended and resort to illegal and often hazardous abortion. The historic rationale of programmes has been to reduce barriers by provision of subsidised services and public information campaigns, and fulfilment of unmet need has been the main driving force behind increased contraceptive use and fertility decline in developing countries (Feyisetan and Casterline 2000). 
There are thus sound theoretical reasons for believing that government family planning programmes can affect fertility but what is the evidence of impact? The effect of national programmes cannot be rigorously assessed by randomised control trials though the results of localised interventions, including quasi-experiments in Matlab, Bangladesh and Northern Ghana, are generally positive (Mwaikambo et al. 2011). The most telling evidence comes from natural experiments where a comprehensive programme has been introduced in a country, often at the initiative of a committed political leader, while a similar country has experienced a weak or non-existent programme. Examples include Tunisia and Algeria, Bangladesh and Pakistan, Kenya and Uganda, and Rwanda and Burundi (Cleland 1994; Blacker et al 2005; Bongaarts et al 2012). In each pair, the first country had a strong programme and recorded an earlier and faster fertility decline than the second. The decline in Bangladesh, starting in the 1980s, is of particular significance because it shows that programmes can be effective even in the poorest and least educated of countries. More recently, Rwanda has replicated the success of Bangladesh; between 2005 and 2010, fertility fell from 6.1 to 4.6 births per women and use of modern methods rose from $10 \%$ to $45 \%$, an astonishing pace of change in a poor country with a strong Roman Catholic presence.

The example of Kenya in the 1980s demonstrates that family size aspirations can change rapidly; in a little more than a decade, average desired family size dropped from 7.2 to 4.8 children and the percentage of married women stating a desire to stop childbearing rose from 16 to 49 percent. This abrupt change suggests that government programmes can directly influence desired family sizes. Supporting evidence is weak, but it is likely that the advent of reproductive choice, in the form of effective contraception, allows a reappraisal of desired number of children which leads to a downwards adjustment. This sequence is a crucial consideration in West Africa, where use of modern methods remains low and desired family sizes high. In this part of Africa, most unmet need for contraception stems from the desire to postpone or space childbearing rather than from the desire to cease altogether. In Asia and Latin America, widening inter-birth intervals contributed little to overall fertility reduction. Africa, however, may differ. Very long birth intervals are largely responsible for the low fertility levels in Southern Africa (Moultie, Sayi \& Timaeus 2012).

In sum, the evidence that government family programmes can accelerate, and less commonly initiate fertility decline, is convincing. In the past 50 years, no poor and ill educated country has experienced a steep and sustained decline in the absence of a strong programme.

One reason, then, for the faltering fertility decline in sub-Saharan Africa has been the failure to implement population policies and promotion of contraception with any conviction or high level political support. The reasons for this policy neglect in Africa stem in part from the most recent international conference on population held in Cairo in 1994. Prior to this conference, rapid population growth was rightly seen as a serious barrier to socio-economic progress and the promotion of family planning was a well funded international development priority. By the early 1990s, considerable progress had been made in reducing birth rates, even in some of the poorest countries, such as 
Bangladesh and Nepal and a sense prevailed that the "population problem" was largely solved. Moreover, success had been achieved at a price. Some Asian family planning programmes were criticized for single-minded promotion of particular methods in pursuit of demographic targets, with little regard for individual choice or the broader issue of reproductive health. In response to these considerations, the pre-eminence of family planning was replaced at the 1994 conference by a more holistic agenda of women's reproductive and sexual rights and health, in which contraception was merely one of many elements. The subsequent demise of family planning as a key development intervention was inevitable but was also hastened by the advent of the AIDS pandemic. International funding and government priorities within Africa shifted to control of this new disease and for much of the past 15 years concerns about population growth and family planning programmes were conspicuously absent from international development discourse.

This era of neglect may be ending. Two large well-attended conferences on family planning have been held in Africa in 2011 and 2012, the first of their kind for well over a decade. In London in July 2012, a family planning summit brought together major donors and developing country leaders to pledge increased funding and visibility.

Signs of recent, rapid change are already evident in East Africa. In addition to Rwanda, contraceptive use among married women in Ethiopia rose from 14\% to 27\% between 2005 and 2011 and in Malawi from 28\% to $42 \%$ over a similarly short period. If the combination of political commitment, international funding and investment to improve information and coverage of services that is responsible for success in these three countries can be replicated in nearby countries, such as Tanzania and Uganda, the UN's low projection for Eastern Africa will be surpassed. In West Africa the pace of change is likely to slower. Adult populations are less well educated, desired family sizes higher, access to services more constrained and attitudes to modern methods less favourable than in Eastern Africa (Cleland, Ndugwa and Zulu 2011).

\section{Implications of future population growth}

A further increase in the world's population of nearly 2 billion is inevitable even if family planning programmes in high fertility countries are re-invigorated. The implications for human welfare and the environment are far reaching but also complex, contested and uncertain. Some of the major issues are outlined below.

Future population growth will stem almost entirely from the world's poorest countries of sub-Saharan Africa and parts of South Asia, whose contributions thus far to global environmental change has been trivial (Satterthwaite 2010). If the dire poverty of these countries persists, then the implications of increased human numbers for planetary trends, such as $\mathrm{CO} 2$ emissions and ocean acidification, will be modest. In modeling the effect of different population scenarios, O'Neill et al. $(2010,2012)$ use the UN's 2004 projections, with high, medium and low mid-century population sizes of 7.4, 8.9 and 10.6 billions, respectively. Their estimates suggest that total CO2 emissions per year in 2050 would be reduced by $15 \%$ if the low rather than the medium population projection 
eventuates. However, as the world's population already exceeds 7 billion and is unlikely to fall below 8.8 billion by mid-century, the $15 \%$ reduction achievable through slower population growth is over-optimistic. Similar results to those of O'Neill are obtained from Tim Jackson's ongoing simulations, cited in Royal Society (2012 pp79-80). Jackson no doubt uses more recent population projections but estimates also suffer from the unrealistic nature of the UN's high, medium and low assumptions.

The verdict is clear. Efforts to shape demographic change can make only a modest contribution to arresting hazardous trends in the planet's environment in the next few decades. Beyond mid-century the impact of population increase could be considerably greater, simply because of the wider divergence in plausible population scenarios. Much depends on income and consumption trends in the rapidly growing populations of subSaharan Africa, North India and Pakistan. Economic growth in Africa has accelerated in recent years partly because of rising commodity prices but also because improved governance has attracted foreign direct investment. Such growth is sorely needed because of the imperative to reduce poverty and hunger but it obviously multiplies the potential environmental consequences of increased population. Reduction of unintended births by promotion of contraception and safe abortion may be one of the most cost effective long term ways of mitigating climate change (Wheeler and Hammer 2010)

Population increase has a more immediate and direct link to the need for increased food production and associated demand for water. Demand for food is driven partly by changing diets but the anticipated rise in the next 40 years of two billion mouths to be fed is a major driver. Conservative forecasts suggest that demand for food will rise by $50 \%$ over this period compared with population increase of $30 \%$. Loss of biodiversity and natural habitats, degradation of fragile eco-systems due to over-cropping and over-grazing and aquifer depletion are likely consequences of this increased demand.

The nexus of population growth, environment, food production and climate change presents the most severe challenge in sub-Saharan Africa. The particularly severe problems of Sahelian countries are discussed by Potts, Hendersen and Campbell in this issue. Agriculture in Africa represents about two-thirds of employment but yields per hectare have remained static for decades. Total production barely kept up with population growth, with the result that many countries are heavily dependent on grain imports. Availability of cropland per person is falling and land degradation is already a problem (World Bank 2008). Undoubtedly, technical solutions to these problems could be found; the historic neglect of African agriculture is ending. But the combination of climate change and population growth is a formidable obstacle to progress. Three quarters of agriculture is rain-fed and is thus vulnerable to increasingly erratic precipitation (Pinstrup-Andersen 2002). Moreover, continued temperature rises will diminish yields most severely in the tropics (IPCC 2007).

While Africa is the only region where a rise in the rural population is expected, most of the increase will occur in cities and towns. Africa's urban population is projected to grow at about 3.5 percent per year for the next 20 years, a rate of increase that implies a doubling in size every 20 years. At present about 36 percent of the region's population 
is urban but this is projected to reach 56 percent by mid-century. Cities are often the engine of economic growth and innovation (Glaeser 2011), though it is uncertain whether this characterisation applies in Africa where urbanisation is driven more by rural poverty than by the attraction of well paid jobs in manufacturing. UN Habitat (2010) estimates that the percentage of Africa's urban dwellers living in informal settlements, or slums, fell from 70 to $62 \%$ between 1990 and 2010, though the absolute number doubled. It is doubtful whether badly needed improvements in urban infrastructure can match the huge projected increase in the urban population.

\section{Conclusion}

In the absence of a catastrophic mortality crisis, a further increase in the world's population from 7 billion to nearly 9 billion is inevitable. About $40 \%$ of this increase will be contributed by Asia, where fertility rates are generally low but where the age structure sustains the number of births. About $46 \%$ will occur in sub-Saharan Africa, the one remaining region with high fertility. In this region the range of uncertainty is wider than elsewhere and the difference between the UN's high and low projections amounts to 470 million by mid-century. If appropriate policies are adopted and programmes implemented, the UN low projection can be achieved and even surpassed.

In addition to the environmental benefits of an accelerated transition to population stabilization in Africa, large health, social and economic benefits would be realized. The number of women dying in childbirth would be cut and child health and education would improve. The ratio of adults to dependent children would rise, creating an opportunity to invest more in agriculture and industry. The promotion of contraception and legitimation of smaller family sizes needs to be one of the top priorities in this region.

\section{References}

Blacker J, Opiyo C, Jasseh M et al. (2005). Fertility in Kenya and Uganda: a comparative study of trends and determinants. Population Studies 59: 355-374.

Bongaarts J, Butatao RA (eds) (2000). Beyond six billion: forecasting the world's population. Washington DC, National Academy Press.

Bongaarts J, Cleland J, Townsend JW et al (2012) Family planning programs for the 21st century: rationale and design. New York, Population Council.

Breton D, Prioux F (2009) The one child family: France in the European context. Demographic Research 20:657-692. 
Campbell MM, Sahin-Hodoglugil NN, Potts M (2006). Barriers to fertility regulation: a review of the literature. Studies in Family Planning 37:87-98.

Casterline JB, Sathar ZA, Haque MU. (1991). Obstacles to contraceptive use in Pakistan: a study in Punjab. Studies in Family Planning 32: 95-110.

Cleland J (1994). Different pathways to demographic transition. In Sir F Graham-Smith (ed) Population; the Complex Reality. London, The Royal Society:229-247.

Cleland J, Ndugwa R, Zulu E (2011). Family planning in sub-Saharan Africa: progress or stagnation? Bulletin of the World Health Organization 89:137-143.

Dyson T (2010). Population and development: the demographic transition. London, Zed Books.

Gillespie D, Ahmed S, Tsui A et al (2007). Unwanted fertility among the poor: an inequity? Bulletin of the World Health Organization 85:100-107.

Glaeser E (2011) Triumph of the city: how our greatest invention made us richer, smarter, greener, healthier and happier. Penguin Books.

IIPS(International Institute for Population Sciences) (2007) National family health survey (NFHS-3) 2005-6. Mumbai, IIPS.

IPCC (2007). Climate change 2007: impacts, adaptation and vulnerability---contribution of working group 2 to the fourth assessment report of IPCC. Cambridge, Cambridge University Press.

Maddison A (2007). Contours of the world's economy. 1-2006 AD. Oxford, Oxford University Press.

Moultrie TA, Sayi TS, Timaeus IM (2012). Birth intervals, postponement, and fertility decline in Africa : a new type of transition? Population Studies 66:241-258.

Mwaikambo L, Speizer IS, Schurmann A et al. (2011) What works in family planning interventions: a systematic review. Studies in Family Planning 42:67-82.

O’Neill BC, Liddle B, Jiang L et al. (2012) Demographic change and carbon dioxide emissions. Lancet 380 (9837):157-164.

O’Neill BC, Dalton, Fuchs R et al. (2010) Global demographic trends and future carbon emissions. PNAS 107:17521-17526.

Pinstrup-Andersen P (2002). Food and agricultural policy for a globalising world: preparing for the future. American Journal of Agricultural Economics 84:1201-1214. 
Potter JE, Berquo E, Perpetuo IHO et al. (2001). Unwanted cesarean sections among public and private patients in Brazil BMJ 323:1155-1158.

Pritchett LH. (1994). Desired fertility and the impact of population policies. Population and Development Review 20:1-56.

Royal Society (2012). People and the Planet. London, Royal Society.

Ruttenberg N, Watkins SC. (1997). The buzz outside the clinics: conversation and contraception in Kenya. Studies in Family Planning 28:290-307.

Satterthwaite D (2010) The implications of population growth and urbanization for climate change. Environment and Urbanization 21:545-567.

Sedgh G, Hussain R, Bankole A et al (2007) Women with an unmet need for contraception in developing countries and their reasons for not using a method. New York, Guttmacher Institute, Occasional Report No. 37.

UN Habitat (2010). State of African cities 2010: governance, inequalities and urban land markets. Nairobi.

UN Population Division (2011a). World Population Prospects: the 2010 Revision. New York.

Walpole SC, Prieto-Merino D, Edwards P et al. (2012) The weight of nations: an estimation of adult human biomass. BMC Public Health 12 (1); 439

Wheeler D, Hammer D (2010). The economics of population policy for carbon emissions reduction in developing countries. Washington DC, Center for Global Development Working Paper No 229.

World Bank (2008). World development report. Washington DC. 
Figure 1 Age structure
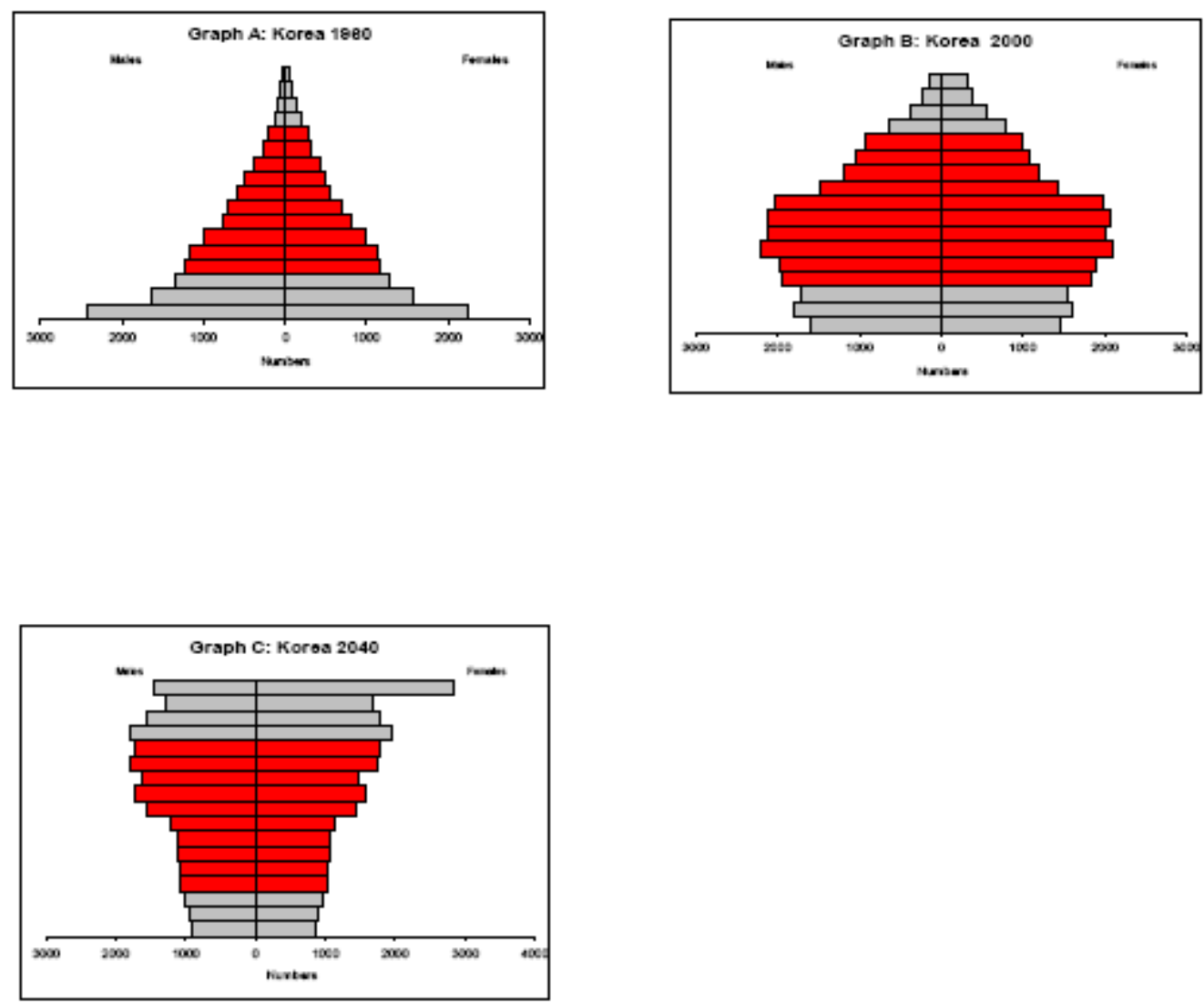


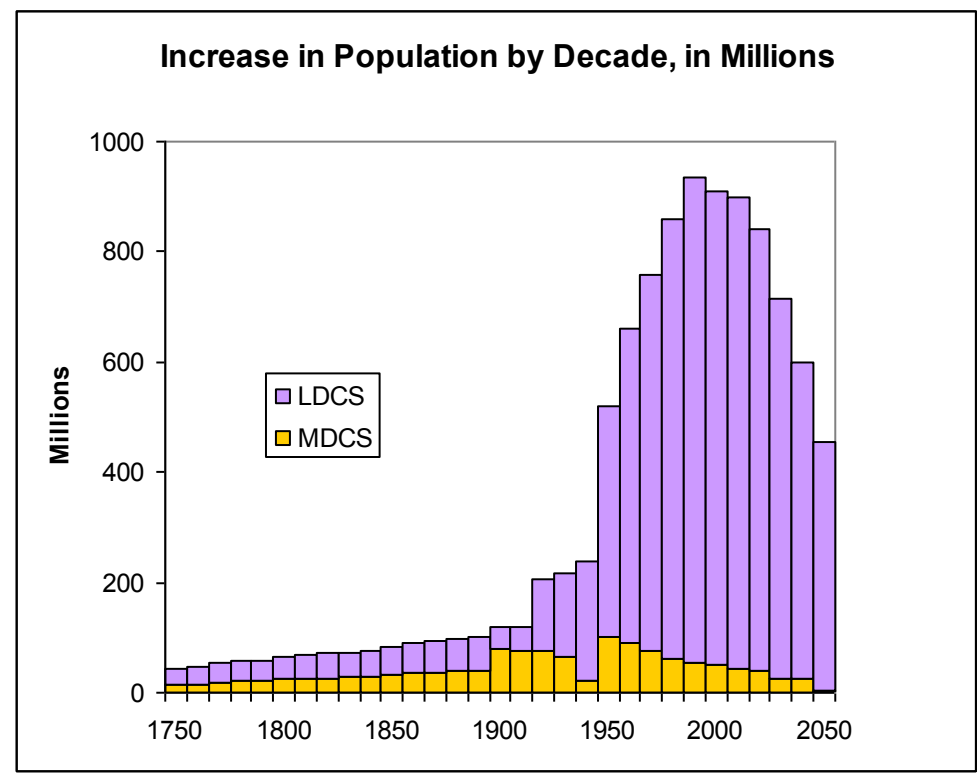

Figure 2 


\begin{tabular}{|l|l|l|l|l}
\hline Region & $\begin{array}{l}\text { Population } \\
1950 \text { (millions) }\end{array}$ & $\begin{array}{l}\text { Population } \\
2010 \text { (millions) }\end{array}$ & $\begin{array}{l}\text { Absolute } \\
\text { increase } \\
\text { (millions) }\end{array}$ & $\begin{array}{l}\text { Ratio } \\
2010 / 1950\end{array}$ \\
\hline Europe & 547 & 738 & 191 & 1.35 \\
\hline $\begin{array}{l}\text { Northern } \\
\text { America }\end{array}$ & 172 & 345 & 173 & 2.00 \\
\hline Asia & 1403 & 4146 & 2743 & 2.96 \\
\hline Latin America & 167 & 590 & 423 & 3.53 \\
\hline Oceania & 13 & 36 & 23 & 2.77 \\
\hline North Africa & 53 & 209 & 156 & 3.94 \\
\hline $\begin{array}{l}\text { Sub-Saharan } \\
\text { Africa }\end{array}$ & 186 & 856 & 670 & 4.60 \\
\hline World & 2532 & 6896 & 4364 & 2.72 \\
\hline
\end{tabular}

Table 1 Population Growth in Major Regions 1950-2010 


\begin{tabular}{|l|l|l|l|l}
\hline Region & Life expectancy & Total fertility & $\begin{array}{l}\text { Annual net } \\
\text { migration } \\
(000 \mathrm{~s})\end{array}$ & $\begin{array}{l}\text { Population } \\
\text { growth rate }\end{array}$ \\
\hline Europe & 75 & 1.53 & 1809 & 0.20 \\
\hline $\begin{array}{l}\text { Northern } \\
\text { America }\end{array}$ & 78 & 2.03 & 1202 & 0.91 \\
\hline Asia & 69 & 2.28 & -1568 & 1.08 \\
\hline Latin America & 73 & 2.30 & -1047 & 1.15 \\
\hline Oceania & 77 & 2.49 & 223 & 1.75 \\
\hline North Africa & 69 & 2.97 & -204 & 1.74 \\
\hline $\begin{array}{l}\text { Sub-Saharan } \\
\text { Africa }\end{array}$ & 52 & 5.10 & -397 & 2.45 \\
\hline World & 68 & 2.52 & 0 & 1.16 \\
\hline
\end{tabular}

Table 2 Demographic Indicators for Major World Regions (2005-2010)

\begin{tabular}{|l|l|l|l|l|l}
\hline Region & $\begin{array}{l}\text { Population } \\
\text { size } \\
\text { (millions) } \\
2010\end{array}$ & $\begin{array}{l}\text { Population } \\
\text { size } \\
\text { (millions) } \\
2050\end{array}$ & $\begin{array}{l}\text { Absolute } \\
\text { change } \\
\text { 2010-2050 } \\
\text { (millions) }\end{array}$ & $\begin{array}{l}\text { Ratio } \\
2050 / 2010\end{array}$ & $\begin{array}{l}\text { Assumed } \\
\text { total fertility } \\
2045-50\end{array}$ \\
\hline Europe & 738 & 719 & -19 & 0.97 & 1.91 \\
\hline $\begin{array}{l}\text { Northern } \\
\text { America }\end{array}$ & 344 & 447 & 103 & 1.30 & 2.07 \\
\hline Asia & 4,164 & 5,142 & 978 & 1.23 & 1.88 \\
\hline $\begin{array}{l}\text { Latin } \\
\text { America }\end{array}$ & 590 & 731 & 161 & 1.27 & 1.79 \\
\hline Oceania & 36 & 55 & 19 & 1.53 & 2.21 \\
\hline North Africa & 209 & 332 & 113 & 1.54 & 2.03 \\
\hline $\begin{array}{l}\text { Sub-Saharan } \\
\text { Africa }\end{array}$ & 856 & 1,960 & 1,101 & 2.29 & 3.00 \\
\hline World & 6,896 & 9,306 & 2,419 & 1.35 & 2.17 \\
\hline
\end{tabular}

Table 3. Population Growth 2010-2050 (United Nations Medium Projection) 